\title{
Living (in) cities of the past: Time travel in Second Life
}

\begin{abstract}
The virtual world Second Life invites residents to plan, build, and maintain their own social geographies. In this article, I draw on data gathered during a multi-year ethnographic study to explore the intersection between memory, nostalgia, place and belonging in Second Life. The article focuses on two packages of land, or 'sims,' owned and designed by a single Second Life resident who is one of most dedicated heritage creators. The 1920s Berlin Project and Time Portal are both popular sims in which physical historical locations are recreated and opened to the public to visit, rent commercial or domestic property and engage in 1920s role play. These sims demand different types of historical engagement. Together, they offer a complex and nuanced portrait of the way Second Life recreates cities of the past.
\end{abstract}

\section{Introduction}

I stand facing two signs. To my left is 1920s Berlin - an arrow points to a train station. To my right, the sign explains, is Time Portal. I can see a futuristic, science-fiction style portal. I am dressed to visit the 1920s. With a smart black dress, rakish hat, and period-appropriate hair, everything is appropriate. Everything, that is, except my feet. My shoes, carefully selected for the occasion, will not attach themselves to my feet. A glitch. Rather than walk around with black heels trailing behind me, I opt to go barefoot. I am visiting one of the most impressive historical districts in the virtual world Second Life. 1920s Berlin and Time Portal are two sims - that is, two packages of virtual land owned and maintained a user who goes by the in-world name Jo Yardley. Together, these sims provide a sense of the multi-faceted ways in which the residents of Second Life recreate, visit, and live with the past.

The desire to return to the past - or at least, to some imagined version of the past - is at the heart of much popular media. Television shows like Downton Abbey reflect and produce a nostalgic yearning for a historical moment which is outside the lived experience of viewers (Baena and Byker 2015; Byrne 2014). Video games set in historical contexts purport to allow players to capture or experience some aspect of the past, with World War II a particularly popular source of historical engagement (Hess 2007). These media offer a means to access history which engages the sense of sight and sound. Their popularity suggests that there is a popular appetite for experiences of historical engagement which are distinct from that available through written histories, whether factual or fictional.

While television, film, and video games offer their own versions of history, in the virtual world Second Life, the desire to experience history can be enacted in a uniquely immersive way. Second Life is a user-created virtual world. As its website proudly proclaims: 
Everything in Second Life - interactive 3D objects, unique experiences, global

communities, and more - is created by people just like you (Linden Lab, n.d.).

Second Life users describe themselves as 'residents' to denote the unique relationship they have to the virtual world. While for many residents, engagement with Second Life is casual and subordinate to offline experiences, others take their residency and lives in Second Life very seriously (e.g. Boellstorff 2008). Residents who are sufficiently skilled in building virtual objects can construct almost anything they can imagine. For the price of an initial investment and a monthly land usage fee, they are able to purchase and use plots of land. As a result, Second Life is full of creatively constructed cities and environments. Some are entirely fantastical, while others mirror or replicate parts of the world offline. This article is concerned with the reconstruction of historical sites and objects for the purposes of roleplaying, re-enacting, or virtual tourism.

This article draws on observations from a larger multi-year ethnographic study into mourning, grief, connectivity, and nostalgia in Second Life (for further results of this research see IDENTIFYING REFERENCE). It contributes to two key areas of literature on historical engagement. The first is the literature on historical themes and ideas in video games (e.g. Hong 2015; Sloan 2015; Rejack 2007; Buinicki 2016; Spring 2015). The second is concerned with historical re-enactment (e.g. Johnson 2015; Brædder et al. 2017). Second Life brings together the interactive digital immersion made possible in video games, with the possibility of deeply-researched and sustained engagement with historical environments, as evident in historical re-enactment. It is a digital space in which reenactment and historical play occurs, but which is not a game in the sense of having a defined storyline or objectives. As such, it allows for a type of encounter with the past which is complex, multifaceted, and ongoing. Hassapopoulou writes that VR docugames allow for the creation of a 'layered, rather than totalizing, experience' $(2018,366)$. The same can be said of Second Life's historical sims, wherein context, residents' prior knowledge of history, and the aesthetic and cultural qualities of the sims themselves combine to create a unique form of engagement with the past.

$<$ Figure 1 about here $>$

Figure 1: Arrows point to 1920s Berlin and Time Portal

\section{Playing with history in Time Portal}

Of the two sites under investigation, Time Portal bears the least resemblance to what may be understood as 'real' history or 'authentic' re-enactment. Time Portal is a playful sim in which visitors use a time machine to travel to a historical destination. Jo Yardley originally described Time Portal as a 'community for Time Travellers and history lovers' where, unlike in 1920s Berlin, there would be no dress code (Yardley 2016). Visitors are encouraged, but not required, to dress according to the time they are visiting. To that end, shops are available in Time Portal destinations, selling periodappropriate clothing.

In visiting Time Portal, a resident becomes a virtual tourist, exploring locales that are temporally and physically distinct from one another, and from the broader venues available in Second Life. Time Portal is described on the Second Life Destination Guide, a guide which lists Second Life's most popular locations, as follows: 
Step through the Time Portals in the laboratory to travel back in time! Train like a gladiator in ancient Rome. See Shakespeare's new play at Tudor London's Globe theatre. Visit a chateau just outside 18th century Paris. Explore the slums of 19th century London. Dance the night away in 1930s New York. Or put a dime in the jukebox at the Diner in 1950s-60s America. And much, much more ("Time Portal" n.d.)

Visitors entering the sim find themselves in a large room reminiscent of science fiction settings (see Figure 1). There is a 'time machine' in the centre of the room and a banner reading 'Time Travellers Society' on one wall. The borders of the room contain portals to historical locations. The precise date and location of these destinations is not always clear. Dates above each portal change, presenting a sense of uncertainty. This serves to construct an expectation of historical inexactness, something that is solidified through descriptions of Time Portal published on the Second Life Destination Guide, such as the entry for Victorian London in the Time Portal, which states that ' $[t]$ he time machine has a virus, so the time zones have been a bit mixed up' ("Victorian London in Time Portal" n.d.). The design of Time Portal is such that visitors do not expect to experience a particular historical moment, but rather a sense of history - a New York which could exist anywhere from the 1920 s to the 1940s, or a place which could be anywhere in America in the 1950s or 1960s.

The lack of enforced dress codes in this sim reinforces the sense of visiting the past, rather than living in it. It is possible to encounter avatars within Time Portal which are wearing clothing that is vastly inappropriate for the setting - or, in some cases, to encounter avatars which are not human at all. Second Life has many thriving roleplaying communities, and it is thus entirely possible for a resident to appear as a vampire, an animal, or even an object.

$<$ Figure 2 about here>

Figure 2: Inside Time Portal

This experience is complicated by the presence of avatars which are not operated by users. These avatars are effectively mannequins, which demonstrate period-appropriate clothing and characteristics. In Figure 2, my avatar visits Time Portal's Tudor London zone while wearing clothing purchased in 1920s-1940s New York. My temporally inappropriate costume contrasts with the more appropriate attire worn by the mannequins in the location. In 1950s-1960s America, mannequins are also present - they stand in the streets and behind kiosks in a movie theatre. These mannequins contribute to the sense of visiting a museum, or a large-scale diorama, rather than a living city.

$<$ Figure 3 about here>

\section{Figure 3: Visiting Tudor London in Time Portal}

In Time Portal, notions of accuracy or authenticity are eschewed in favour of the development of spaces which provide an affective sense of 'pastness.' Visitors walk through streets and buildings which are 'authentic' in the sense that they could have existed, not in the sense that they are real. Jo Yardley has 'done history' in this space through producing a sense of the past, rather than painstakingly attempting to recreate the past itself. Time Portal is thus akin to an open-air museum. It presents some real historical places, like the Globe theatre, alongside artefacts and settings which 
provide a sense of what history may have been like. It encourages and welcomes visitors, and its layout is such that it is possible to engage with the space without any prior knowledge or preparation. Its similarity to a museum is further evidenced by the transient nature of resident engagement in Time Portal - while this sim is active, it does not host a well-developed and cohesive role-playing community.

\section{'Pastness,' community, and re-enactment in 1920s Berlin Project}

Unlike Time Portal, which seeks to create a sense of 'pastness', the 1920s Berlin Project replicates a very specific time and place. Its description on the Second Life Destination Guide reads:

Travel back in time to this big city during an amazing era. Wander down Unter den Linden, explore the dirty old back streets, see a movie at the cinema, visit the museum, enjoy cabaret, dance the Charleston in a small Tanzlokal or at the gay Eldorado club in this role-play sim with a 1920s dress code (freebies provided) (“The 1920s Berlin Project" n.d.)

Like Time Portal, it presents itself as a locale for virtual tourism - a place in which it is possible to visit the past and engage in activities which would have been enjoyed by the people who lived in a bygone era. Unlike the Time Portal locations, however, the 1920s Berlin Project requires that visitors adhere to a temporally appropriate dress code. As such, there is a demand for visitors to the 1920s Berlin Project to invest in and partake of the imagined authentic engagement with history made possible by this space through changing the appearance of their avatars. While the enforcement of community standards of dress is unusual, it is common for residents of virtual worlds to select avatars which demonstrate their affiliation with their chosen communities (Martey and Consalvo 2011). As such, the dress code in the 1920s Berlin Project may be understood as reinforcing existing norms within Second Life as well as demanding a type of digitally embodied engagement with the theme of the sim.

Another key difference between Time Portal and the 1920s Berlin Project is the longevity of the latter. While Time Portal was created in 2016, the 1920s Berlin Project has been open since 2009. As a result, while it welcomes virtual tourists, 1920 s Berlin also has a community of long-term residents. Most of the buildings have apartments, which are rented to Second Life residents who wish to live in the community. These residents pay in Lindens, the Second Life currency, which can be exchanged for real-world money. In a 2016 interview, Yardley stated that the apartments have been 'almost permanently fully occupied since day one.' Yardley has been able to pay for her monthly land usage fee, also known as a tier, through the rental fees paid by residents. In this sense, 1920s Berlin is financially self-sustaining. There are thus two groups of users in 1920s Berlin. There are tourists, who may visit the city, but do not live in it. There is also a group of people who live in 1920 s Berlin, either renting apartments or, if they don't have the funds or inclination, visiting the sim on a regular basis.

The presence of a community of residents demonstrates the ongoing demand for virtual recreations of historical places. It also, however, demonstrates the limits of historical accuracy in the creation and sustainment of historical sims. There is no expectation that all residents of 1920 s Berlin undertake their own historical research. While there are community rules and guidelines in place, there is nothing to prevent residents from speaking or acting in ways which are anachronistic. 
Previous research in virtual worlds has demonstrated the longevity of virtual communities, as well as their impact on the identities of their members (e.g. Boellstorff 2008; Pearce 2009). The long-term members of the 1920s Berlin community are shaped by their identification with this sim, just as they shape the sim itself.

Many of the long-term residents of 1920s Berlin have well-established identities and roles within the community. Residents do not generally recreate specific historical figures. Instead, they take on roles, living lives which could have existed. As such, they do not recreate history as it actually occurred. Instead, they engage in a type of historical play which produces an encounter with the feeling of past contexts and possibilities.

1920s Berlin has a police force, a criminal underworld, a dance troupe, and a staffed primary school. It has its own newspaper and an often-busy calendar of social events. At major events, residents often partake in a form of roleplaying which resembles soap opera performance. For example, during my fieldwork in 2016 , I attended an engagement party at which the glamorous mother of the groom made a dramatic speech about the fact that the groom's father had recently died. Other guests gossiped about their (virtual) lives and acquaintances. Events in 1920s Berlin thus feature a type of performativity, where residents imagine and enact what it would be like to live as an (often wealthy) person in Berlin in the 1920s.

They also, however, reveal the very real and meaningful connections between residents who participate in this space. In a 2016 interview, Yardley stated that, while she constructed the city herself, the community was built by the members. She said that the community is sufficiently close that, when a long-term resident dies or disappears, the community often comes together to hold a memorial service. The community even has its own cemetery, in which it can memorialise deceased members. Yardley's efforts to construct an authentic historical setting have therefore encouraged the development of a community which is bound by shared playfulness and real friendship.

Residents are drawn to the community both by the historical theme and by the extraordinarily detailed environment provided in this space. As one resident told me during my fieldwork, 'it's a marvel.' One enters 1920s Berlin for the first time from a train. Figure 4 shows my avatar arriving in 1920s Berlin. The train platform on which I arrive depicts a level of detail which is evident throughout the sim. The virtual world allows for a kind of precision in world-building which is not possible in other settings. Yardley has outlined her method for recreating some of the realistic buildings in her sim which, in the case of buildings which have been demolished or substantially altered, involves the use of older photographs, paintings, and drawings (Yardley 2015). In doing so, she draws on the concepts of historical research and authenticity in order to explain and validate her aesthetic and practical choices. This framing of the 1920s Berlin Project suggests that its residents re-enact history in a space which is vast, detailed, and as close to reality as the technology of Second Life will allow.

The reality, however, is far more complicated. The 1920s Berlin Project offers residents the opportunity to live in a past time and place. In doing so, it also allows them to shape identities and practices which are rooted in personal, often idealised, understandings of history and a desire for play. It also provides a leaping-off point for some residents to develop a stronger understanding of the physical, historical, environment which their virtual community replicates. As one long-term resident told me during my fieldwork in 2016:

For some it becomes more important over time. [...] Well they join because they like the idea of being a 1920s flapper and just dance a bit or go to a party. And then they stay, 
and then they learn more, and then suddenly they are reading big fat books about the Weimar Republic.

While not every resident of the 1920s Berlin Project will go on to undertake this type of additional reading, the possibility of residents altering their understandings of the historical context and their mode of engagement with 1920s Berlin suggests that any totalising understanding of this environment - as playful, or educational, or authentic, or false - will fail to capture its complexity.

<Figure 4 about here>

Figure 4: Arriving in 1920s Berlin

\section{Digitally mediated history}

These Second Life sims highlight the both possibilities and limitations of digitally mediated history, and particularly of digitally mediated historical re-enactment. They demonstrate that virtual worlds such as Second Life provide an environment in which it is possible to construct realistic representations of past places. They also, however, show that ideas of accuracy and authenticity become troubled in a context in which communities shape and alter the environments in which they reside.

Video games have been suggested as a potential medium for the dissemination of historical scholarship (Spring 2015). They may gesture toward historical authenticity through the inclusion of real people, places, and events, and may even encourage players to take on the role of real historic figures or groups . Participating in historical games has been likened to traditions of historical reenactment (Rejack 2007). As with physical re-enactment, there is a divide between the way in which academics, including historians and cultural-heritage practitioners, and the developers of games perceive accuracy and how it should be measured in the context of historical video games (Copplestone 2017). Similarly, the question of accuracy - how important it is, and whether it can be measured - remains open in relation to Second Life's historical sims. Their representation of history is always shaped by the knowledge and skill of their creators, the technological limitations of Second Life itself and, perhaps most significantly, by the activities and desires of the residents who use them.

The key defining aspect of the video game experience is the presence of set objectives. Players may be more or less free to explore an environment, but the world they visit is defined by objectives. Engagement with history in his way can be powerful. For example, Buinicki (2016) shows that, in the popular video game Bioshock Infinite, nostalgic imagery is used in an imagined future context, exposing the way in which nostalgia can cover up racial and other injustices. Bioshock Infinite does not attempt to replicate history accurately, but instead engages with historical themes and ideas. This use of history, Buinicki argues, 'collapses the distance between American society and the dystopia of the game,' reinforcing 'the idea that the alternative history of Columbia is disturbingly similar to the dominant historical narrative: the racism and the nationalism that lead to the oppressive dystopia in the clouds has roots in US history' $(2016,730)$. Part of the impact of this game is the very fact that players have limited agency in relation to the outcomes of the narrative. They cannot free themselves from the past 'even if they cannot - or choose not to - remember it' (Buinicki 2016, 732). 
In this sense games are like films and television shows, which, where they engage with history, present a pre-formed narrative to audiences. The nature of games requires that historical characters, places, and items are given a defined structure and fit within a logical order wherein they can be interpreted and interacted with by players (Schut 2007, 223). Second Life, as a virtual world without pre-defined objectives, does not offer such an order or structure. The visitors and residents of Time Portal and 1920s Berlin do not enter into a world which is pre-formed and pre-defined. Instead they enter into a world which is very like the physical world - one which has rules of engagement, and consequences for breaking those rules, but which is otherwise open. It is this context which allows, and indeed encourages, residents to form sustained relationships and to live (digital) past lives.

Gapps notes that 'reenactors are charmed not by the original, but by its authentic simulation' $(2009,398)$. That is, original historical artefacts are less valuable in re-enactment than simulations, because the simulations do not show signs of age. They are more 'authentic' in the sense that they better replicate the look and feel of the item as it would have been experienced in its lifetime. In Second Life, there is no pretence of offering the original. The simulation is all that is possible. Yet, in a location in which everything is simulated, the authentic historical simulation takes on a different meaning. Reenactment can involve various forms of proximity to the past, including proximity based on closeness to past material realities and proximity based on authenticity of experience (Brædder et al. 2017, 185). In Second Life, there is no expectation of closeness to material reality. Residents know that they cannot pick up or touch past artefacts online. Virtual re-creations also do not enable the type of experiential connection to past bodies made possible through wearing historical garb or partaking in embodied activities such as sewing (e.g. Johnson 2015, 200). Despite this, Second Life has been shown in educational settings to allow for a unique form of engagement with historical contexts (e.g. Cloutier 2018).

Key to Second Life's promise as a means of accessing and experiencing the past is not its ability to claim authenticity, but its low barriers to entry and its ability to allow for sustained engagement. Residents of Second Life do not need to make or purchase costumes or engage in research before they visit Time Portal. While they are required to wear period-appropriate attire in 1920s Berlin, a basic accepted outfit is provided to them free of charge. Further, there is no need for extended preparation. As long as an individual has access to a computer and an internet connection, they are able to enter Second Life's historical sims. These sims do not offer the same opportunities for the experience of authenticity as physical re-enactment. However, they allow for a different type of engagement with the past which is equally, albeit differently, powerful. Residents of Second Life are able to live in and with cities of the past - to return to them at will - and, in some cases, to experience them as a mundane, but valuable, aspect of daily life.

\section{Moral histories}

Time Portal and 1920s Berlin allow for a type of historical engagement which is more sustained and mundane than that offered in video games or even in physical forms of re-enactment. However, the very fact that, unlike games, they do not have a plot, also limits the capacity of these sites to engage with the moral issues present in the histories they explore. As shown in Figure 5, 1920s Berlin has very specific rules about the way in which visitors may dress and behave. In particular, its rules against weapons and uniforms ensure that the dark side of Berlin in the 1920s - including the emergence of Nazism - cannot be openly portrayed and discussed. 
$<$ Figure 5 about here>

Figure 5: 1920s Berlin rules

Interestingly, 1920s Berlin has what may be described as a seedy underbelly, featuring nightclubs, drinking, and crime. Both 1920s Berlin and Time Portal contain much that is self-consciously luxurious in terms of clothing offered for sale and locations which may be visited. This is part of the appeal of these sites. There is, in these spaces, a tension between a sense of self-indulgence and danger, which may be understood as 'immoral' within the constraints of some more conservative moral codes, and an absence or obscuring of the pressing moral questions of the periods represented.

This is not to state that the Second Life sites entirely avoid historical reality. On designated occasions, residents may roleplay major events. For example, Yardley organises an annual reenactment of the 1929 Blutmai riots in 1920s Berlin (Yardley 2018). However, these events are planned out in advance and participants come to them knowing what to expect. In their day-to-day lives, residents of 1920s Berlin can be assured that, if anyone attempts to breach the peace, they will be swiftly removed from the sim by a moderator. This is necessary in an environment in which people of all ages are welcome to visit and spend time. There is none of the capacity for surprise available in games.

Moral engagement with history is made possible by the narratives of some games which take historical settings. Games like Bioshock Infinite and Assassin's Creed: Freedom Cry have been shown to force players to engage with immoral histories real and imagined, and in doing so, to encourage players to consider similar moral issues in present contexts (Buinicki 2016; Hammar 2017). During my fieldwork, one long-term resident of 1920 s Berlin told me that he learned far more about the history of Germany and Nazism as a result of his engagement with the space. However, this was largely the result of additional reading and searching. It was not part of the experience offered to casual visitors.

In an important sense, the realms of the Time Portal and 1920s Berlin may be understood as antithetical to the type of trauma tourism which can be enacted in other commemorative and historical sites in Second Life, such as the Holocaust memorial (e.g. Trezise 2012). In the historical sims under examination, traumatic historical events are eschewed in favour of spaces which are created to be enjoyed. This further highlights the limits of accuracy as a means of measuring and understanding virtual engagement with the past. However, this obscuring of historical moral tensions and traumas is not without its physical equivalents. This practice is similar to the forms of re-enactment which exist offline in large-scale or open-air museums where, as Barndt (2007) has shown, approaches to presenting and understanding history are rooted in present concerns and tastes.

\section{Conclusion}

Time Portal and the 1920s Berlin Project provide two very different means of experiencing history in the virtual world Second Life. Both, however, are created by the same person, who expresses a commitment to engaging in solid historical research and providing an authentic experience of history. Johnson argues that: 
While re-enactors' obsession with historical accuracy is often mocked in academia, something of the rigour academic historians value in our archival research reverberates in re-enactors' attention to historical accuracy in the items they create $(2015,198)$.

In one sense, same can be said about creators, like Jo Yardley, who seek to create an authentic sense of 'pastness' for visitors and community members, justifying their claims to authenticity through processes of research and careful reconstruction \{Citation\}. However, visitors come to sites like Time Portal and 1920s Berlin with very different motives and levels of investment in historical accuracy. The result is the creation of a type of engagement with the past which is nuanced, complex, and immersive. Here, authenticity, even if it is valued by the sim's creator, must give way to the needs and desires of the community.

Residents in 1920s Berlin and Time Portal engage with history in a playful, creative way, similar to that identified in other re-enacting contexts (Brædder et al. 2017, 187). However, the fact that this is a digital space means that barriers to entry are low and engagement can occur over a long period. It is possible for residents to 'do' history in many, smaller, chunks of time.

The nature of Second Life - its emphasis on user-created content and its lack of specific objectives - allows for a different type of historical engagement than is possible in traditional video games, and a more interactive type of engagement than that offered by books or television. In Second Life, it is possible to present and experience a version of the past which is 'layered' and changing, rather than totalising or didactic (Hassapopoulou 2018, 366). As such, Second Life's historical spaces do not aim to present academic 'history'. Instead, they allow residents to live in cities of the past in ways which are impossible elsewhere. 


\section{References}

Baena, Rosalía, and Christa Byker. 2015. "Dialects of Nostalgia: Downton Abbey and English Identity." National Identities 17 (3): 259-69. https://doi.org/10.1080/14608944.2014.942262.

Barndt, Kerstin. 2007. "Fordist Nostalgia: History and Experience at The Henry Ford." Rethinking History 11 (3): 379-410. https://doi.org/10.1080/13642520701353330.

Boellstorff, Tom. 2008. Coming of Age in Second Life: An Anthropologist Explores the Virtually Human. Princeton: Princeton University Press.

Brædder, Anne, Kim Esmark, Tove Kruse, Carsten Tage Nielsen, and Anette Warring. 2017. “Doing Pasts: Authenticity from the Reenactors' Perspective." Rethinking History 21 (2): 171-92. https://doi.org/10.1080/13642529.2017.1315969.

Buinicki, Martin T. 2016. "Nostalgia and the Dystopia of History in 2K's Bioshock Infinite." The Journal of Popular Culture 49 (4): 722-37. https://doi.org/10.1111/jpcu.12440.

Byrne, Katherine. 2014. "Adapting Heritage: Class and Conservatism in Downton Abbey." Rethinking History 18 (3): 311-27. https://doi.org/10.1080/13642529.2013.811811.

Cloutier, Joe. 2018. "Marginalized Urban Indigenous Youth and the Virtual World of Second Life: Understanding the Past and Building a Hopeful Future." Journal For Virtual Worlds Research 11 (3). https://doi.org/10.4101/jvwr.v11i3.7322.

Copplestone, Tara Jane. 2017. "But That's Not Accurate: The Differing Perceptions of Accuracy in Cultural-Heritage Videogames between Creators, Consumers and Critics." Rethinking History 21 (3): 415-38. https://doi.org/10.1080/13642529.2017.1256615.

Fogu, Claudio. 2009. "Digitalizing Historical Conscience." History and Theory 48 (2): 103-21. https://doi.org/10.1111/j.1468-2303.2009.00500.x.

Gapps, Stephen. 2009. "Mobile Monuments: A View of Historical Reenactment and Authenticity from inside the Costume Cupboard of History." Rethinking History 13 (3): 395-409. https://doi.org/10.1080/13642520903091159.

Hammar, Emil Lundedal. 2017. "Counter-Hegemonic Commemorative Play: Marginalized Pasts and the Politics of Memory in the Digital Game Assassin's Creed: Freedom Cry." Rethinking History 21 (3): 372-95. https://doi.org/10.1080/13642529.2016.1256622.

Hassapopoulou, Marina. 2018. "Playing with History: Collective Memory, National Trauma, and Dark Tourism in Virtual Reality Docugames." New Review of Film and Television Studies 16 (4): 365-92. https://doi.org/10.1080/17400309.2018.1519207.

Hess, Aaron. 2007. “'You Don't Play, You Volunteer': Narrative Public Memory Construction in Medal of Honor: Rising Sun." Critical Studies in Media Communication 24 (4): 339-56. https://doi.org/10.1080/07393180701567729.

Hong, Sun-ha. 2015. "When Life Mattered: The Politics of the Real in Video Games' Reappropriation of History, Myth, and Ritual." Games and Culture 10 (1): 35-56. https://doi.org/10.1177/1555412014557542. 
Johnson, Katherine M. 2015. "Rethinking (Re)Doing: Historical Re-Enactment and/as Historiography." Rethinking History 19 (2): 193-206. https://doi.org/10.1080/13642529.2014.973709.

Linden Lab. n.d. "Bring Your Creativity to Life." Second Life. http://go.secondlife.com/landing/creator/?lang=en.

Martey, Rosa Mikeal, and Mia Consalvo. 2011. "Performing the Looking-Glass Self: Avatar Appearance and Group Identity in Second Life." Popular Communication 9 (3): 165-80. https://doi.org/10.1080/15405702.2011.583830.

Pearce, Celia. 2009. Communities of Play: Emergent Cultures in Multiplayer Games and Virtual Worlds. Cambridge, Mass: MIT Press.

Rejack, Brian. 2007. "Toward a Virtual Reenactment of History: Video Games and the Recreation of the Past." Rethinking History 11 (3): 411-25. https://doi.org/10.1080/13642520701353652.

Schut, Kevin. 2007. "Strategic Simulations and Our Past: The Bias of Computer Games in the Presentation of History." Games and Culture 2 (3): 213-35. https://doi.org/10.1177/1555412007306202.

Sloan, Robin J. S. 2015. "Videogames as Remediated Memories: Commodified Nostalgia and Hyperreality in Far Cry 3: Blood Dragon and Gone Home." Games and Culture 10 (6): 525-50. https://doi.org/10.1177/1555412014565641.

Spring, Dawn. 2015. "Gaming History: Computer and Video Games as Historical Scholarship." Rethinking History 19 (2): 207-21. https://doi.org/10.1080/13642529.2014.973714.

"The 1920s Berlin Project." n.d. Second Life. Accessed September 7, 2018. http://secondlife.com/destination/1828.

“Time Portal." n.d. Second Life. Accessed September 7, 2018. http://secondlife.com/destination/time-portal.

Trezise, Bryoni. 2012. "Touching Virtual Trauma: Performative Empathics in Second Life." Memory Studies 5 (4): 392-409. https://doi.org/10.1177/1750698011426355.

"Victorian London in Time Portal." n.d. Second Life. Accessed September 18, 2018. http://secondlife.com/destination/victorian-london-in-time-portal.

Yardley, Jo. 2015. "Using Virtual Reality to Rebuild the Past, Reconstructing the Zum Nussbaum Restaurant." Jo Yardley's Second Life (blog). May 22, 2015. https://joyardley.wordpress.com/2015/05/22/using-virtual-reality-to-rebuild-the-pastreconstructing-the-zum-nussbaum-restaurant/.

- - . 2016. "Time Portal." Jo Yardley's Second Life (blog). August 8, 2016. https://joyardley.wordpress.com/category/time-portal/.

-- - 2018. "Blutmai Riots Are Coming!” The 1920s Berlin Project (blog). April 21, 2018. https://1920sberlinproject.wordpress.com/2018/04/21/blutmai-riots-are-coming/. 

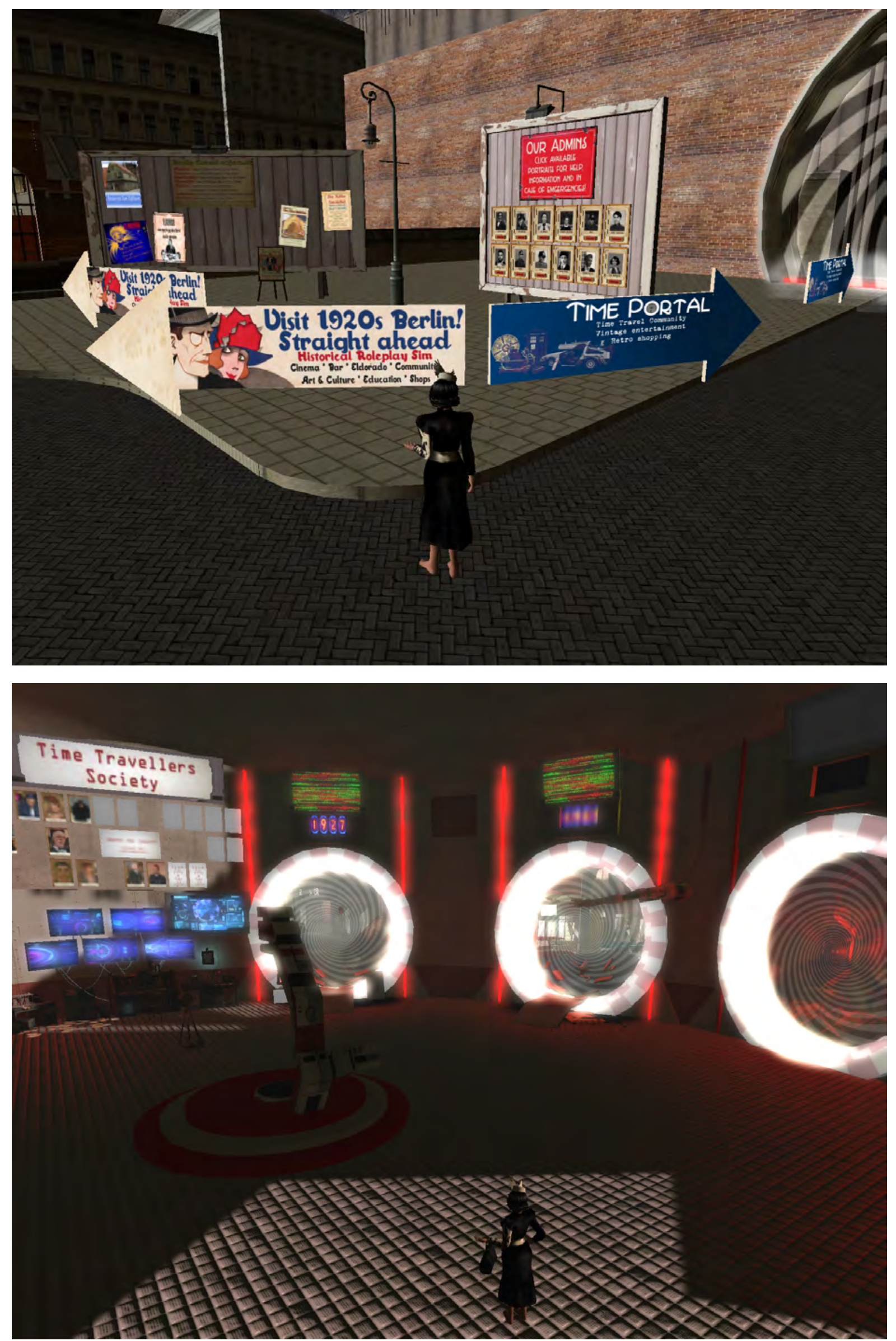

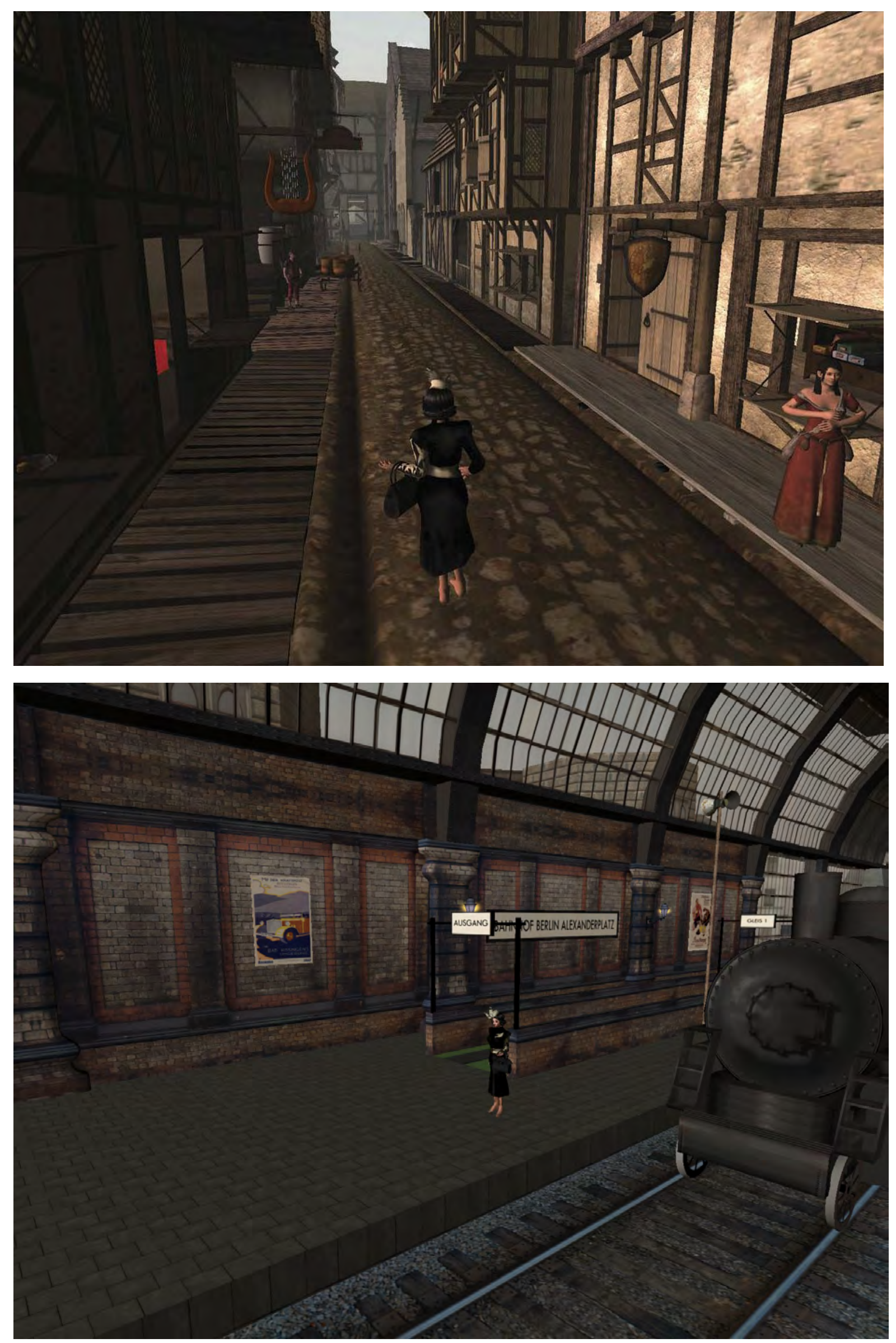


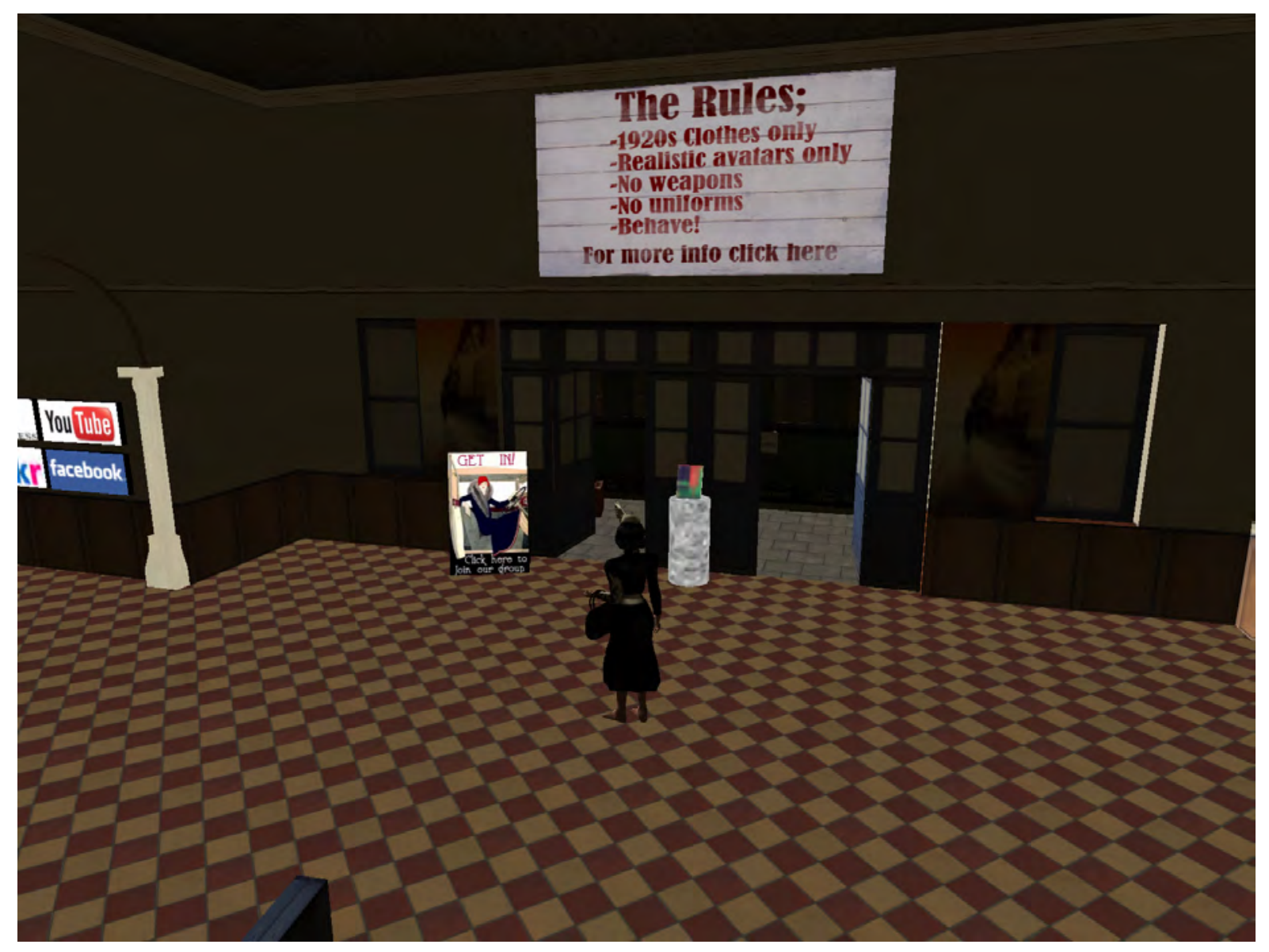

